\title{
Anti-Nucleosome Antibody Measurement
}

National Cancer Institute

\section{Source}

National Cancer Institute. Anti-Nucleosome Antibody Measurement. NCI Thesaurus.

Code C120627.

The determination of the anti-nucleosome antibody present in a sample. 